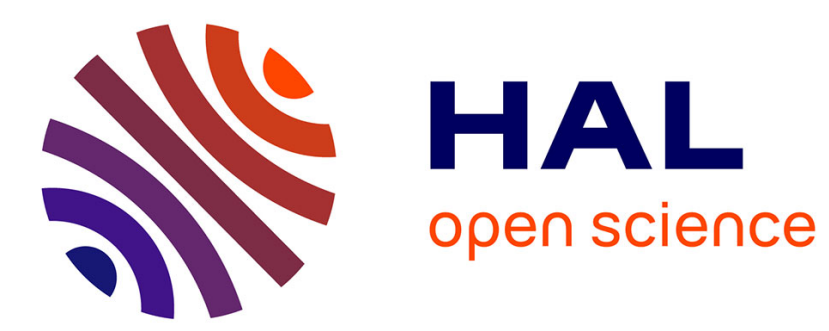

\title{
Mise en ligne des IEP du groupe des chambres à bulles (hydrogène)
}

\author{
J.F. Gay, E. Jecham, A. Michalon
}

\section{To cite this version:}

J.F. Gay, E. Jecham, A. Michalon. Mise en ligne des IEP du groupe des chambres à bulles (hydrogène). Revue de Physique Appliquée, 1969, 4 (2), pp.327-327. 10.1051/rphysap:0196900402032700 . jpa00243286

\section{HAL Id: jpa-00243286 https://hal.science/jpa-00243286}

Submitted on 1 Jan 1969

HAL is a multi-disciplinary open access archive for the deposit and dissemination of scientific research documents, whether they are published or not. The documents may come from teaching and research institutions in France or abroad, or from public or private research centers.
L'archive ouverte pluridisciplinaire HAL, est destinée au dépôt et à la diffusion de documents scientifiques de niveau recherche, publiés ou non, émanant des établissements d'enseignement et de recherche français ou étrangers, des laboratoires publics ou privés. 


\title{
MISE EN LIGNE DES IEP DU GROUPE DES GHAMBRES A BULLES (HYDROGÈNE)
}

\author{
J. F. GAY, E. JEGHAM et A. MICHALON, \\ Département de Physique Corpusculaire, C.R.N., Strasbourg.
}

Résumé. - Nous nous proposons de décrire très brièvement le système de mise en ligne employé par le Groupe des Chambres à Bulles de Strasbourg. Cette opération a été décidée dans le but d'améliorer de façon sensible le rendement et de parfaire le système de mesures, sans toutefois augmenter notablement les frais de fonctionnement. Les "IEP " ont été connectés à un ordinateur IBM 1800 de 16000 mots de mémoire. Cette mise en ligne est actuellement opérationnelle pour trois IEP. Le système, relativement complexe, permet l'instauration d'un dialogue assez élaboré entre l'ordinateur et les opérateurs de mesure, en utilisant des informations contenues sur des "cartes de scanning". Des précautions particulières ont été prises afin que toute panne sur un canal (appareils de mesures, interface, périphériques de l'ordinateur) n'arrête pas le fonctionnement des autres appareils, et afin qu'en aucun cas une panne n'entraîne des pertes de mesures. Les premiers résultats d'exploitation montrent que la capacité de mesure du groupe a été sensiblement multipliée par deux.

Abstract. - In order to improve the quality of it measurements and to increase notably the efficiency, the Bubble Chamber Group (hydrogen) has worked out the on-line operation of its measurement devices with an IBM 1800 computer working in real time. A sophisticated dialogue has been established between the computer and the operator, in order that one can have a precise guide of measurement which avoids the errors of handling, although he has the quite indispensable initiative in order to make satisfactorily the measurements of events which have significant singularities.

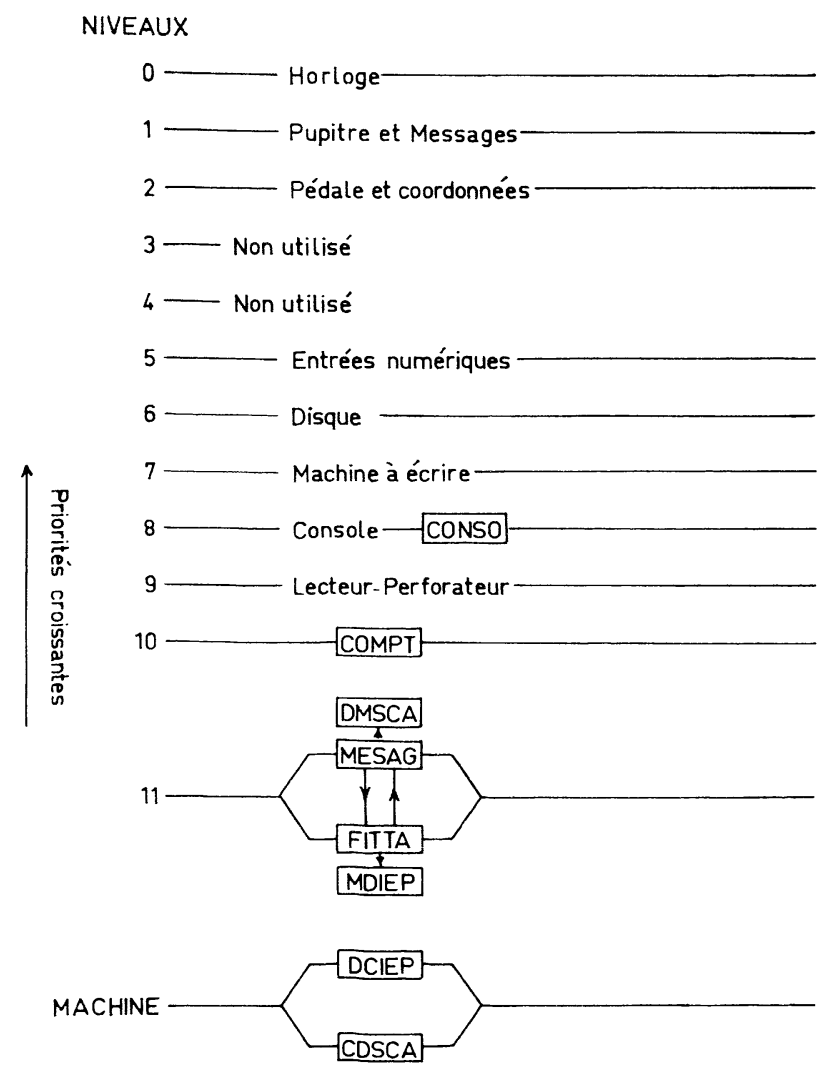

FIG. 1. - Agencement des niveaux de priorité. 